\title{
HYVÄKSYMIS- JA OMISTAUTUMISTERAPIAN TYÖKALUJEN HYÖDYNTÄMINEN TERVEYSSOSIAALITYÖSSÄ
}

Kati Kauravaara: LitT, valtiotieteiden kandidaatti/sosiaalityön opiskelija, Helsingin yliopisto

kati.kauravaara@liikuntafysio.fi

Janus vol. 28 (1) 2020, 85-93

Asiakas: Selkäni on niin kipeä, etten voi tehdä juuri mitään. En usko, että nyt on ajankohtaista miettiä, mihin voisin mennä työkokeiluun. Hyvä, kun selviän arjesta kotona. En käy enää kaupassakaan, saati vesijuoksemassa, mitä tykkäsin aiemmin tehdä, koska pelkään, milloin kipu iskee.

Sosiaalityöntekijä: Huomaan, että sinulla on ajatus, että kipu estää sinua tekemästä sellaisia asioita, joista pidät. Mitä jos kuvittelisit hetken ajan, että kipu on kuin rantapallo, jonka kanssa kamppailet vedessä. --- Et pidä rantapallosta ja haluat sen pois elämästäsi. Niinpä yrität painaa rantapalloa veden alle, jotta et näkisi sitä ja jotta se $p y-$ syisi poissa tietoisuudestasi. Kuitenkin rantapallo pyrkii aina takaisin veden pinnalle, ja siitä syystä joudut käyttämään molempia käsiäsi ja paljon voimaa, jotta saat pallon pysymään pois näkyvistäsi. Pallon pitäminen veden alla pitää pallon samalla lähellä sinua. Mitäpä jos antaisit rantapallon tulla pintaan? Pallo saattaisi ajelehtia lähellä sinua, mistä et ehkä pitäisi. On kuitenkin myös mahdollista, että rantapallo ajautuisi vähitellen sinusta kauemmas. Jos päästäisit rantapallosta irti, olisi sinulla ainakin mahdollisuus käyttää käsiäsi paremmin vedessä, eivätkä aikasi ja voimasi kuluisi pallon pitämiseen pinnan alla pois näkyvistä.

(Metafora rantapallosta, mukailtu Jepsen 2012)

Edellä olevan kaltaisen keskustelun terveyssosiaalityöntekijä voisi käydä asiakkaansa kanssa. Vuoropuhelu on samalla esimerkki siitä, kuinka sosiaalityöntekijä voi hyödyntää hyväksymis- ja omistautumisterapian työkaluja asiakastyössään.

Hyväksymis- ja omistautumisterapian työkaluja käytetään laajasti ympäri maailmaa sairauksien hoidossa ja kuntoutuksessa sekä terveyden ja hyvinvoinnin edistämisessä - myös Suomessa. Hyväksymis- ja omistautumisterapian käyttöä on tutkittu paljon psykiatristen ja somaattisten sairauksien hoidossa, ja vaikuttavuusnäyttöä on osoitettu lukuisilla tutkimuksilla (esim. A-Tjak ym. 2015; Montgomery ym. 2011; Powers ym. 2009; Öst 2014).Vaikka metaanalyysit osoittavat, että hyväksymis- ja omistautumisterapia on vaikuttavampi kontrolliryhmiin verrattuna, sen ei ole kaikissa tehdyissä meta-analyyseissä todettu olevan vaikuttavampi kuin muut empiirisesti todennetut psykososiaaliset hoitomuodot, kuten perinteinen kognitiivinen käyttäytymisterapia (ATjak ym. 2015; Powers ym. 2009; Öst 2014). Kuitenkin on olemassa myös sellaisia löydöksiä, joissa hyväksymisja omistautumisterapia on kognitiiviseen käyttäytymisterapiaan verrattuna vaikuttavampi (esim. Ruiz 2012). Hyväksymis- ja omistautumisterapia on tunnustettu muun muassa American Psychological Association -järjestön näyttöön perustuvaksi menetelmäksi (APA Presidential Task Force on 
Evidence-Based Practice 2006; APA Society of Clinical Psychology 2018). Erityisesti esimerkiksi kroonisen kivun hoidossa on saatu korkeaa vaikuttavuusnäyttöä (Feliu-Soler ym. 2018; Hann \& McCracken 2014; Veehof ym. 2011;Veehof ym. 2016; Öst 2014).

Sosiaalityöntekijöitä on kannustettu hyväksymis- ja omistautumisterapian työkalujen käyttämiseen (esim. Boone 2014; Boone ym. 2015; Dewane 2008; 2012; Montgomery ym. 2011), ja niitä onkin hyödynnetty sosiaalityön kontekstissa jonkin verran ainakin Yhdysvalloissa ja Kanadassa. Suomessa sosiaalityöntekijät ovat tutustuneet aiheeseen toistaiseksi niukasti. Suomalaisen tutkimuksen mukaan terveyssosiaalityöntekijät näkevät ylipäänsä psykososiaalisen tuen antamisen olevan merkittävä osa heidän työtään. Suuri osa tutkimukseen osallistuneista kuitenkin koki, että he käyttivät omaa asiantuntijuuttaan vähiten juuri tällä alueella, ja moni halusi panostaa enemmän psykososiaaliseen työskentelyyn asiakkaiden kanssa. (Korpela 2014.)

Tässä puheenvuorossani kuvaan hyväksymis- ja omistautumisterapian lähtökohtia ja annan joitakin esimerkkejä hyväksymis- ja omistautumisterapian työkalujen käyttöalueista erityisesti terveyssosiaalityön kontekstissa. Rajaan tarkasteluni koskemaan terveyssosiaalityötä, jota tehdään erityisesti aikuisten parissa tuki- ja liikuntaelimistön kuntoutuksen yksiköissä.

\section{KOHTI PSYKOLOGISTA JOUSTAVUUTTA}

Hyväksymis- ja omistautumisterapia luetaan kuuluvaksi niin sanottuihin kolmannen aallon kognitiivisiin käyttäytymisterapiamenetelmiin (Hayes 2004a; 2016), ja se perustuu suhdekehysteoriaan (Hayes ym. 2001). Suhdekehysteoriassa selitetään teoreettisesti kieltä ja kognitioita eli ihmisen mieltä. Kielen ja ajattelun ajatellaan olevan opittua ja kontekstuaalisesti hallittua taitoa yhdistää erilaisia asioita ja tapahtumia toisiinsa sen mukaan, miten nämä tapahtumat suhteutuvat toisiinsa sekä vuorovaikutuksellisiin tilanteisiin ja tapahtumiin ihmisen elämässä. (Hayes ym. 2006.)

Kun ihmiset liittävät asioita toisiinsa, he samalla tekevät asioista erilaisia johtopäätöksiä usein tiedostamatta ja usein ilman, että niistä on itsellä suoria kokemuksia. Suhdekehysteorian mukaan ihmisen kielelliset toiminnot eli esimerkiksi se, että asioiden välille voidaan luoda kielen avulla suhteita, kansanomaisemmin ihmisen mieli, aiheuttaa suuren osan niistä kärsimyksistä, joita koemme. Se johtuu siitä, että kielellisiä prosesseja ja ongelmanratkaisua hyödynnetään tiedostamatta myös silloin, kun ne eivät toimi tai niillä on huonoja seurauksia, kuten epämiellyttävien ajatusten ja tunteiden kontrolloimisessa. (Hayes ym. 2001; Hayes ym. 2006; Tuomisto \& Lappalainen 2015, 85, 88.) Usein kontrolloimisesta seuraa ajatusten ja tunteiden tai niitä aiheuttavien kokemusten välttäminen, mikä alkaa hiljalleen kapeuttaa elämää eikä yleensä toimi pitkällä aikavälillä. Automaattisia sisäisiä tapahtumia, kuten ajatuksia ja tunteita, on tutkimusten mukaan vaikea hallita,ja välttämisyritykset johtavat usein päinvastaiseen eli ajatusten ja tunteiden lisääntymiseen. (Hayes ym. 1996; Hayes 2016; Wegner 1994.) 
Hyväksymis- ja omistautumisterapian työkalujen avulla pyritään erityisesti lisäämään psykologista joustavuutta (Hayes ym. 2006), mikä on tärkeä mekanismi, jonka kautta saadaan aikaan hyödyllisiä ja myönteisiä vaikutuksia ihmisen hyvinvointiin ja kliinisiin oireisiin (Ciarrochi ym. 2010). Psykologisen joustavuuden lisäämiseen pyritään kuuden prosessin avulla: hyväksyntä, mielen kontrollin tai kielellisyyden heikentäminen, tietoinen läsnäolo nykyhetkessä, havainnoiva minä, arvojen kirkastaminen sekä sitoutuminen omien arvojen mukaiseen toimintaan. Prosessit limittyvät toisiinsa ja menevät osin päällekkäin. (Hayes ym. 2006; Hayes ym. 2012.) Kaikki kuusi prosessia voidaan nähdä myös taitoina, kuten taulukosta 1 käy ilmi.

Taulukko 1. Hyväksymis- ja omistautumisterapian prosessit taitoina (mukailtu esimerkiksi lähteistä Hayes ym. 2006; Hayes ym. 2012; Hayes \& Smith 2008; Lappalainen ym. 2013).

\begin{tabular}{|c|c|}
\hline Prosessi & Taito \\
\hline Hyväksyntä & $\begin{array}{l}\text { Kykyä ottaa vastaan kaikenlaisia sisäisiä } \\
\text { tapahtumia juuri sellaisina kuin ne kyseisellä } \\
\text { hetkellä ovat ilman tarvetta kontrolloida tai } \\
\text { muuttaa omia ajatuksia tai tunteita. }\end{array}$ \\
\hline Mielen kontrollin heikentäminen & $\begin{array}{l}\text { Kykyä tunnistaa sisäisten tapahtumien } \\
\text { vaikutusta omaan toimintaan, tulla tietoiseksi } \\
\text { omasta automaattisesta tavasta ajatella ja taitoa } \\
\text { irrottautua sisäisten tapahtumien vaikutuksesta } \\
\text { käyttäytymiseen. }\end{array}$ \\
\hline Tietoinen läsnäolo nykyhetkessä & $\begin{array}{l}\text { Taitoa elää tässä ja nyt murehtimatta menneitä } \\
\text { tai huolehtimatta tulevasta. Kykyä keskittyä ja } \\
\text { havainnoida nykyhetkeä arvostelematta, } \\
\text { tuomitsematta ja muuttamatta sitä sekä taitoa } \\
\text { tarvittaessa palauttaa levoton mieli takaisin } \\
\text { nykyhetkeen. }\end{array}$ \\
\hline Havainnoiva minä & $\begin{array}{l}\text { Taitoa havainnoida itseä ja oman mielen } \\
\text { tuottamia sisäisiä tapahtumia ml. käsityksiä } \\
\text { itsestä. Taitoa löytää tila, jossa voi huomata } \\
\text { itsensä ajattelemassa ajatuksia, tuntemassa } \\
\text { tunteita, kokemassa kokemuksia jne. Taitoa } \\
\text { irrottautua voimakkaiden käsitysten } \\
\text { ohjausvallasta ja mielikuvista. }\end{array}$ \\
\hline Arvojen kirkastaminen & $\begin{array}{l}\text { Kykyä huomata ja selkiyttää, mikä on } \\
\text { arvokasta, itselle tärkeää, hyvää elämää. }\end{array}$ \\
\hline $\begin{array}{l}\text { Sitoutuminen omien arvojen mukaiseen } \\
\text { toimintaan }\end{array}$ & $\begin{array}{l}\text { Kykyä tehdä sellaisia konkreettisia valintoja ja } \\
\text { tekoja, jotka ovat linjassa omien arvojen kanssa } \\
\text { ja joilla on siten myönteistä vaikutusta omaan } \\
\text { hyvinvointiin. Kykyä tehdä omien arvojen } \\
\text { mukaisia valintoja mahdollisista epämukavista } \\
\text { sisäisistä tapahtumista huolimatta tai niiden } \\
\text { kanssa. }\end{array}$ \\
\hline
\end{tabular}


Hyväksymis- ja omistautumisterapiassa psykologisen joustavuuden lisäämiseen käytetään konkreettisia työkaluja, jotka voivat olla esimerkiksi kokemuksellisia harjoitteita, tietoisuustaitoharjoituksia, metaforia, lomakkeita ja kotitehtäviä. Lähestymistavan ja työkalujen välinen suhde käy ilmi kuviosta 1. Työkalut lisäävät psykologista joustavuutta auttamalla asiakkaita saamaan kontaktin

\section{ESIMERKKEJÄ TYÖKALUJEN} HYÖDYNTÄMISESTÄ TERVEYSSOSIAALITYÖNTEKIJÄN TYÖSSÄ

Arvotyöskentelyssä eli prosesseissa arvojen kirkastaminen sekä sitoutuminen omien arvojen mukaiseen toimintaan asiakkaan on mahdollista löytää toiminnalleen mielekkyys ja merkitys. Merkityksen löytyminen vahvistaa asi-

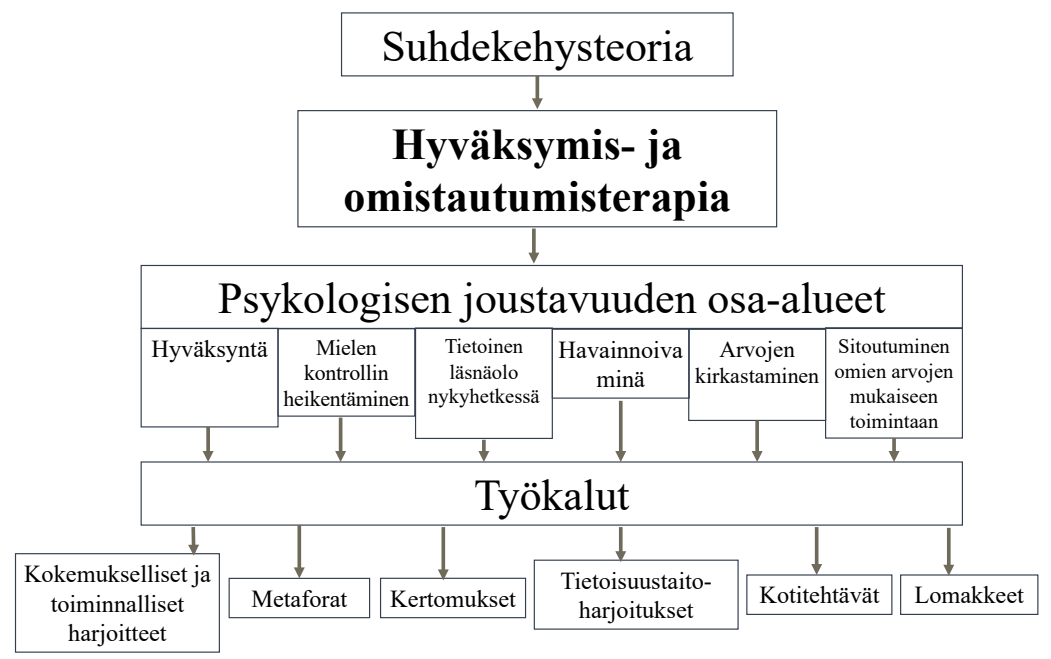

Kuvio 1. Hyväksymis- ja omistautumisterapian suhteutuminen suhdekehysteoriaan, psykologisen joustavuuden osa-alueisiin sekä työkaluihin.

joustamattomuutta ilmentäviin kielellisiin haasteisiin, purkamaan kielellisesti syntyneitä asioiden, ajatusten, tunteiden, kehon tuntemusten ja kokemusten välisiä suhteita ja siten heikentämään kielellisyyden merkitystä ja vaikutusta asiakkaan kannalta ongelmallisilla elämänalueilla sekä vahvistamaan oppimista oman kokemuksen kautta. (Hayes 2004b, 15; Hayes ym. 2006.) akkaan sitoutumista prosessiin. (Twohig 2012.) Arvotyöskentelyn avulla sosiaalityöntekijä voi tukea asiakkaan motivaation suuntautumista sellaisiin asioihin ja tekoihin, jotka edistävät asiakkaan kuntoutumista. Asiakas saattaa esimerkiksi oivaltaa, että hän haluaa olla vielä mukana työelämässä ja löytää itselleen mielekkään uuden ammatin ja sen takia kokea tärkeäksi kuntouttaa itseään. 
Usein suoraviivaista arvojen mukaista toimintaa hidastavat tai haittaavat erilaiset mielen tuottamat esteet. Minkälaisia nämä esteet sitten voivat olla?

Asiakas: Olen selkäsairas, eivätkä fysioterapeutin antamat harjoitteet luonnistu kotona. Sosiaalityöntekijä: Sinulla näyttää olevan ajatus itsestäsi selkäsairaana.

Asiakas: Niin, minulla on ajatus, että olen selkäsairas.

Sosiaalityöntekijä: Mitä havaintoja teet, jos miellät sen, että olet selkäsairas, ajatukseksesi siitä, että olet selkäsairas?

Asiakas: Hmmm --- se tuntuu paremmalta: se on vain ajatus. Olenhan minä muutakin kuin selkäsairas!

Sosiaalityöntekijä: Juuri niin. Entäpä jos muutat lauseen vielä tuohon muotoon, jonka kirjoitin paperille?

Asiakas: Huomaan, että minulla on ajatus, että olen selkäsairas...

Sosiaalityöntekijä: Miltä tämä virke nyt kuulostaa?

(Harjoitus "Minulla on ajatus" mukailtu Hayes \& Smith 2008; Pietikäinen 2016, 111)

Asiakas saattaa samaistua käsitykseensä itsestään eli siihen, että hän on sairas tai vaivainen. Mielessään hän saattaa liittää sanoihin sairas tai vaivainen tiettyjä ominaisuuksia. Hänellä saattaa olla uskomus, ettei sairas pysty tekemään esimerkiksi fysioterapeuttisia harjoitteita kotona, vaikka se auttaisi hänen tilannettaan. Tällöin sosiaalityöntekijä voi työskennellä asiakkaan kanssa niin, että asiakkaan on mahdollista irrottautua voimakkaiden käsitysten ohjausvallasta. Havainnoivan minän prosessiin liittyvässä työskentelyssä asiakas saa käsitykseensä "olen selkäsairas" uudenlaista perspektiiviä ja voi kyseenalaistaa itse arvionsa itsestään, mikä mahdollistaa uudenlaisen käyttäytymisen.

Mielen kontrollin heikentämiseen liittyvät kokemukselliset harjoitteet auttavat tulemaan tietoiseksi omasta automaattisesta tavasta ajatella ja irrottautumaan ajatusten, tunteiden tai vaikkapa kehon tuntemusten vaikutuksesta käyttäytymiseen. Jos aikaisemmin asiakkaan voimavarat olivat ohjautuneet esimerkiksi sellaisten tilanteiden välttämiseen, joissa kipua esiintyy, hänen on nyt mahdollista opetella tekemään arvojen viitoittamaa suuntaa palvelevia valintoja mahdollisesta kivusta huolimatta tai pikemminkin kivun kanssa. (Hayes ym. 2013.)

Kroonisesta kivusta kärsivän ihmisen käyttäytymiseen usein liittyvä välttäminen tunnistetaan yhdeksi kipuun pohjautuvan kärsimyksen peruselementiksi (McCracken \& Samuel 2007). Hyväksyntä on ikään kuin välttämisen vastakohta (Hayes ym. 2006; Hayes ym. 2013). Hyväksynnän voidaan kroonisen kivun yhteydessä luonnehtia olevan sitä, että ihminen oppii elämään kivun kanssa ilman, että reagoi kipuun, arvioi tai arvostelee kipua, yrittää vähentää tai välttää sitä (McCracken 1998). Kivun hyväksyminen ei tarkoita sitä, että alistuisi kivulle tai olisi piittaamatta kivusta, vaan sitä, että haluaa sitoutua tekemään itselleen mielekkäitä asioita läsnä olevan kivun kanssa (Cederberg ym. 2015).Yksi esimerkki hyväksynnän lisäämiseen tähtäävästä työkalusta on johdannon alun vuoropuhelusta löytyvä metafora rantapallosta. Työskenneltäessä mielen tuottamien esteiden kanssa kuljetaan kohti ihmisen itsensä kannalta mielekästä elämää, joka voi lopulta 
mahdollistaa myös esimerkiksi työhön paluun.

\section{LOPUKSI}

Näen, että hyväksymis- ja omistautumisterapian konkreettiset työkalut soveltuvat terveyssosiaalityöntekijän käytettäväksi erityisesti psykososiaalisen tuen välineenä, vaikka työkalujen hyödyntäminen edellyttää erityistä perehtymistä.

Boone kumppaneineen (2015) listaavat neljä syytä, miksi hyväksymis- ja omistautumisterapian työkalut sopivat hyvin kliinisen sosiaalityön käytäntöihin. Ensinnäkin työkalujen käytettävyys on laaja, sillä niitä hyödynnetään monimuotoisesti lukuisilla eri alueilla, kuten psyykkisten ja fyysisten sairauksien hoidossa ja kuntoutuksessa sekä elintapojen muuttamisessa, kuten tupakoinnin lopettamisessa ja painonhallinnassa. Toiseksi hyväksymis- ja omistautumisterapian käytettävyydestä ja vaikuttavuudesta on lupaavaa kasvavaa tutkimusnäyttöä. Kolmanneksi hyväksymis- ja omistautumisterapia on yhdenmukainen sosiaalityön arvojen kanssa: esimerkiksi ihminen ymmärretään osana hänen sosiaalista ja fyysistä ympäristöään ja asiakkailla ja työntekijöillä on yhteisiä piirteitä, koska he molemmat ovat saman kielellisen järjestelmän sisällä ja siten tasa-arvoisia. Neljänneksi hyväksymis- ja omistautumisterapian työkalujen käyttäminen on helppo aloittaa, sillä paljon kirjallisuutta ja työkaluja on kenen tahansa saatavilla. (Boone ym. 2015.) Viimeinen kohta viittaa siihen, että lähestymistapaa kehittävä tutkija- ja ammattilaisyhteisö, Association for Contextual Behavio- ral Science (ASBC), on päättänyt, ettei se anna virallista tutkintoa tai lisenssiä menetelmää käyttäville ammattilaisille (Boone ym. 2015; Hayes \& Smith 2008, 235).

Perustelut ovat mielestäni toimivia myös Suomessa. On kuitenkin syytä olla tietoinen siitä, että yhdysvaltalaisissa tutkimuksissa hyväksymis- ja omistautumisterapiaa hyödynnetään nimenomaan kliinisessä sosiaalityössä. Kliinistä sosiaalityötä tehdään erityisesti mielenterveystyön kontekstissa, jossa terapeuttinen työote on keskeistä. (Tapola-Haapala 2017.) Suomessa sosiaalityön perusorientaatio on ollut hyvin yhteiskuntatieteellisesti painottunutta, jolloin sosiaalityön psykologinen ja psykososiaalinen ulottuvuus ovat jääneet vähemmälle painoarvolle (Lähteinen ym. 2017; Kananoja 2017; Mäntysaari ym. 2009).

Terveyssosiaalityöntekijä saattaa kokea aluksi työkalujen hyödyntämisen itselleen vieraaksi, kun ei ole saanut psykologista tai psykoterapeuttista peruskoulutusta. Silti työkaluja kannattaa mielestäni hyödyntää silloin, kun ne ovat asiakkaan näkökulmasta toimivia. Jo tällä hetkellä työkaluja käytetään myös terveydenhuollon ulkopuolella esimerkiksi elintapojen muuttamisen tukemisessa. Tällöin ollaan tekemisissä hyvinvoinnin, terveyden ja toimintakyvyn edistämisen kanssa. Markkinoilla on myös lukuisa määrä suoraan kuluttajalle suunnattuja itsehoito-oppaita, joiden avulla harjoituksiin pääsee käsiksi omatoimisesti. Siten ammattilaisen ei tarvitse pelätä sitä, että hän toimii alueella, jolla ei pitäisi. Sosiaalityöntekijä ei myöskään toimi psykoterapeuttina ilman asianmukaista koulutusta. Am- 
mattitaitoa on osata ohjata asiakas tarvittaessa eteenpäin, mikäli herää epäilys siitä, että asiakas tarvitsisi psykiatrin, psykologin tai psykoterapeutin apua.

Käytännönläheisiä ja konkreettisia työkaluja ei liene koskaan liikaa sosiaalityöntekijän arjessa. Siksi haluankin rohkaista suomalaisia terveyssosiaalityöntekijöitä hyödyntämään osana muuta ammatillista osaamistaan hyväksymis- ja omistautumisterapian työkaluja omassa työssään siinä yhteydessä, jossa ne tuntuvat toimivilta.

\section{KirJallisuUs}

APA Presidential Task Force on Evidence-Based Practice (2006) Evidencebased practice in psychology. American Psychologist, 61 (4), 271-285. https:// doi.org/10.1037/0003-066X.61.4.271

APA Society of Clinical Psychology (2018) Psychological treatments. https://www. div12.org/treatments/.Luettu 13.1.2019.

A-Tjak, Jacqueline G. L. \& Davis, Michelle, L. \& Morina,Nexhmedin \& Powers, Mark B. \& Smits, Jasper A. J. \& Emmelkamp, Paul M. G. (2014) A Meta-analysis of the efficacy of acceptance and commitment therapy for clinically relevant mental and physical health problems. Psychotherapy and Psychosomatics 84, 30-36. https:// doi.org/10.1159/000365764

Boone, Matthew S. (toim.) (2014) Mindfulness and acceptance in social work. Evidence-based interventions and emerging applications. The mindfulness and acceptance practica. Oakland: New Harbinger Publications.

Boone, Matthew S. \& Mundy, Brian \& Stahl, Kate Morrissey \& Genrich, Bethany E. (2015) Acceptance and commitment therapy, functional contextualism, and clinical social work. Journal of $\mathrm{Hu}-$ man Behavior in the Social Environment 25, 643-656. https://doi.org/10.1080/1 0911359.2015.1011255

Cederberg, Jenny Thorsell \& Cernvall,
Martin \& Dahl, Joanne \& von Essen, Louise \& Ljungman, Gustaf (2015) Acceptance as a mediator for change in acceptance and commitment therapy for persons with chronic pain? International Journal of Behavioral Medicine 23 (1), 21-29. https://doi.org/10.1007/ s12529-015-9494-y

Ciarrochi, Joseph \& Bilich, Linda \& Godsell, Clair (2010) Psychological flexibility as a mechanism of change in acceptance and commitment therapy. Teoksessa Ruth Baer (toim.) Assessing mindfulness and acceptance: Illuminating the processes of change. Oakland: New Harbinger Publications, 51-76.

Dewane, Claudia (2008) The ABCs of ACT - Acceptance and Commitment Therapy. Social Work Today 8 (5), 34-37.

Feliu-Soler, Albert \& Montesinos, Francisco \& Gutiérrez-Martínez, Olga \& Scott, Whitney \& McCracken, Lance M. \& Luciano, Juan V. (2018) Current status of acceptance and commitment therapy for chronic pain: A narrative review. Journal of Pain Research 11, 2145-2159. https://doi.org/10.2147/JPR.S144631

Hann, Katie E. J. \& McCracken, Lance M. (2014) A Systematic review of randomized controlled trials of Acceptance and Commitment Therapy for adults with chronic pain: Outcome, domains, design quality, and efficacy. Journal of Contextual Behavioral Science 3 (4), 217-227. https://doi.org/10.1016/j. jcbs.2014.10.001

Hayes, Steven C. (2004a) Acceptance and commitment therapy, relational frame theory, and the third wave of behavioral and cognitive therapies. Behavioral Therapy 35 (4), 639-665. https://doi. org/10.1016/S0005-7894(04)80013-3

Hayes, Steven C. (2004b) Acceptance and commitment therapy and the new behavior therapies. Mindfulness, acceptance and relationship. Teoksessa Steven C. Hayes \& Victoria M. Follette \& Marsha M. Linehan (toim.) Mindfulness and acceptance. Expanding the cognitive-behavioral tradition. New York: The Guilford Press, 1-29.

Hayes, Steven C. (2016) Acceptance and commitment therapy, relational frame theory, and the third wave of behavio- 
ral and cognitive therapies. Republished article. Behavioral Therapy 47 (4), 869-885. https://doi.org/10.1016/j. beth.2016.11.006

Hayes, Steven C. \& Barnes-Holmes, Dermot \& Roche, Bryan (toim.) (2001) Relational frame theory. A Post-Skinnerian account of human language and cognition. New York: Kluwer Academic/Plenum Publishers co. https://doi. org $/ 10.1007 /$ b108413

Hayes, Steven C. \& Levin, Michael E. \& Plumb-Vilargata, Jennifer \& Villatte, Jennifer \& Pistorello, Jacqueline (2013) Acceptance and commitment therapy and contextual behavioral science: Examing the progress of a distinctive model of behavioral and cognitive therapy. Behavior Therapy 44 (2), 180-198. https://doi. org/10.1016/j.beth.2009.08.002

Hayes, Steven C. \& Luoma, Jason B. \& Bond, Frank W. \& Masuda, Akihiko \& Lillis, Jason (2006) Acceptance and commitment therapy: Model, processes and outcomes. Behaviour Research and Therapy 44 (1), 1-25. https://doi. org/10.1016/j.brat.2005.06.006

Hayes, Steven C. \& Smith, Spencer (2008) Vapaudu mielesi vallasta ja ala elää hyväksymis- ja omistautumisterapian avulla. Suom. Päivi ja Raimo Lappalainen. 7. painos. SKT:n julkaisusarja: Hoitomenetelmien julkaisuja 8.1. Tampere: Suomen Käyttäytymistieteellinen Tutkimuslaitos Oy.

Hayes, Steven C. \& Strosahl, Kirk \& Wilson, Kelly G. (2012) Acceptance and commitment therapy: The process and practice of mindful change. 2. uudistettu painos. New York: The Guilford Press.

Hayes, Steven C. \& Wilson, Kelly G. \& Gifford, Elizabeth V. \& Follette,Victoria M. \& Strosahl, Kirk (1996) Experiential avoidance and behavioral disorders: a functional dimensional approach to diagnosis and treatment. Journal of Consulting and Clinical Psychology 64 (6), 11521168. https://doi.org/10.1037/0022006X.64.6.1152

Jepsen, Matthew (2012) Ball in a pool. Teoksessa Jill A. Stoddard \& Niloofar Afari. The Big book of ACT Metaphors. A practioner's guide to experiental exercises \& metaphoras in acceptance and commitment therapy. Oakland: New Harbinger Publications.

Kananoja, Aulikki (2017) Sosiaalityö terveydenhuollossa. Teoksessa Aulikki Kananoja \& Martti Lähteinen \& Pirjo Marjamäki (toim.) Sosiaalityön käsikirja. 4. uudistettu painos. Helsinki: Tietosanoma Oy, 347-356.

Korpela, Rauni (2014) Terveyssosiaalityön asiantuntijuus ja kehittäminen. Teoksessa Anna Metteri \& Heli Valokivi \& Satu Ylinen (toim.) Terveys ja sosiaalityö. Jyväskylä: PS-kustannus, 101-118.

Lappalainen, Raimo \& Lehtonen, Tuula \& Hayes, Steven C. \& Batten, Sonja \& Gifford, Elizabeth \& Wilson, Kelly G. \& Afari, Niloofar \& McCurry, Susan M. (2013) Hyväksymis- ja omistautumisterapia käytännön terapiatyössä. Applying acceptance and commitment therapy (ACT). A Clinical manual. 9. painos. SKT:n julkaisusarja: Hoitomenetelmien julkaisuja 3.1. Tampere: Suomen Käyttäytymistieteellinen Tutkimuslaitos Oy.

Lähteinen, Sanna \& Raitakari, Suvi \& Hänninen, Kaija \& Kaittila, Anniina \& Kekoni, Taru \& Krok, Suvi \& Skaffari, Pia (2017) Sosiaalityön koulutuksen tuottama osaaminen. SOSNET julkaisuja 7. Rovaniemi: Valtakunnallinen sosiaalityön yliopistoverkosto Sosnet.

McCracken, Lance M. (1998) Learning to live with the pain: acceptance of pain predicts adjustment in persons with chronic pain. Pain 74 (1), 21-27. https://doi. org/10.1016/S0304-3959(97)00146-2

McCracken, Lance M. \& Samuel, Victoria M. (2007) The role of avoidance, pacing, and other activity patterns in chronic pain. Pain 130 (1), 119-125. https://doi. org/10.1016/j.pain.2006.11.016

Montgomery, Katherine L. \& Kim, Johnny S. \& Franklin, Cynthia (2011) Acceptance and commitment therapy for psychological and physiological illnesses: A systematic review for social workers. Health \& Social Work 36 (3), 169-181. https://doi.org/10.1093/hsw/36.3.169

Mäntysaari, Mikko \& Pohjola, Anneli \& Pösö, Tarja (toim.) (2009) Sosiaalityö ja teoria. Jyväskylä: PS-kustannus.

Pietikäinen, Arto (2016) Joustava mieli. Vapaudu stressin, uupumuksen ja masennuksen ylivallasta. 1.-24. painos. Onni- 
sarja. Helsinki: Kustannus Oy Duodecim. Powers, Mark B. \& Zum Vörde Sive Vörding, Maarten B. \& Emmelkamp, Paul M. G. (2009) Acceptance and commitment therapy: A meta-analytic review. Psychotherapy and psychosomatics 78 (2), 7380. https://doi.org/10.1159/000190790

Ruiz, Francisco J. (2012) Acceptance and commitment therapy versus traditional cognitive behavioural therapy: A systematic review and meta-analysis of current empiric evidence. International Journal of Psychology \& Psychological Therapy 12 (2), 333-357.

Tapola-Haapala, Maria (2017) Yhdysvaltalainen clinical social work kulttuurisena ilmiönä. Teoksessa Maija Jäppinen \& Anna Metteri \& Satu Ranta-Tyrkkö \& Pirkko-Liisa Rauhala (toim.) Kansainvälinen sosiaalityö. Käsitteitä, käytäntöjä ja kehityskulkuja. Sosiaalityön tutkimuksen vuosikirja 2016. 2. painos. Helsinki: UNIpress, 76-101.

Tuomisto, Matti T. \& Lappalainen, Raimo (2015) Kognitiivinen käyttäytymisterapia.Teoksessa Matti O. Huttunen \& Hely Kalska (toim.) Psykoterapiat. 3. uudistettu painos. Helsinki: Kustannus Oy Duodecim, 83-105.

Twohig, Michael P. (2012) Introduction: The basics of acceptance and commitment therapy. Cognitive and Behavioral Practice 19, 499-507. https://doi. org/10.1016/j.cbpra.2012.04.003

Veehof, Martine M. \& Oskam, MaartemJan \& Schreurs, Karlein M. G. \& Bohlmeijer, Ernst T. (2011) Acceptance-based interventions for the treatment of chronic pain: A systematic review and metaanalysis. Pain 152 (3), 533-542. https:// doi.org/10.1016/j.pain.2010.11.002
Veehof, Martine M. \& Trompetter Hester R. \& Bohlmeijer, Ernst T. \& Schreurs, Karlein M. G. (2016) Acceptance- and mindfulness-based interventions for the treatment of chronic pain: A meta-analytic review. Cognitive Behaviour Therapy 45 (1), 5-31. https://doi.org/10.1080 /16506073.2015.1098724

Wegner, Daniel M. (1994) Ironic processes of mental control. Psychological Review 101 (1), 34-52. https://doi. org/10.1037/0033-295X.101.1.34

Öst, Lars-Göran (2014) The Efficacy of acceptance and commitment therapy: An updated systematic review and meta-analysis. Behaviour Research and Therapy 61, 105-121. https://doi. org/10.1016/j.brat.2014.07.018

Kirjoitus on lyhennelmä maaliskuussa 2019 Helsingin yliopistossa hyväksytystä sosiaalityön kandidaatin tutkielmasta. Kandidaatin tutkielman nimi on Hyväksymis- ja omistautumisterapian työkalujen hyödyntäminen terveyssosiaalityössä ja se on luettavissa kokonaisuudessaan verkossa. 